\title{
Avaliação de Estados de Humor nos Exames da Royal Academy of Dance
}

\author{
Priscila Raquel Tedesco da Costa Trevisan ${ }^{1}$ \\ Gisele Maria Schwartz \\ Danielle Ferreira Auriemo \\ LEL - Laboratório de Estudos do Lazer \\ Universidade Estadual Paulista, Campus de Rio Claro \\ Marcelo Fadori Soares Palhares \\ FHO - Uniararas \\ LEL - Laboratório de Estudos do Lazer \\ Universidade Estadual Paulista, Campus de Rio Claro \\ Norma Ornelas Montebugnoli Catib \\ FIRA - Faculdades Integradas Regionais de Avaré \\ LEL - Laboratório de Estudos do Lazer \\ Universidade Estadual Paulista, Campus de Rio Claro \\ Ivana de Campos Ribeiro \\ LEL - Laboratório de Estudos do Lazer \\ Universidade Estadual Paulista, Campus de Rio Claro
}

\begin{abstract}
RESUMO - Este estudo qualitativo investigou os estados de humor de alunos participantes dos Exames da Royal Academy of Dance. A pesquisa exploratória utilizou o POMS (Profile of Mood States), aplicado antes e após o exame, a uma amostra intencional composta por 12 estudantes de dança, faixa etária de 18 a 40 anos. A análise descritiva, ao se comparar os dados obtidos no pré e pós-teste, evidenciou um aumento da fadiga e uma diminuição do vigor e índices mínimos dos estados de tensão, depressão, raiva e confusão mental. Novos estudos se fazem necessários, visando ao aprimoramento das abordagens acerca dos estados subjetivos envolvendo as práticas, a formação em dança e as avaliações das performances, aspectos ainda pouco explorados em âmbito acadêmico.
\end{abstract}

Palavras-chave: estados de humor, dança, avaliações

\section{Assessment of Mood States in the Royal Academy of Dance Examination System}

\begin{abstract}
This qualitative study investigated the mood states of students, participants in of the Royal Academy of Dance examinations. The exploratory research used the POMS (Profile of Mood States), administered before and after the examination, to an intentional sample of 12 dance students, aged 18 to 40 years. The descriptive analysis, comparing the data collections in the pre and post-test showed an increase in fatigue and decreased vigor and minimum indices of tension states, depression, anger and confusion. Further studies are needed in order to improve the approaches to the subjective states involving practice, background training in dance and performance assessments, aspects largely unexplored in the academic ambit.
\end{abstract}

Keywords: mood states, dance, evaluation

O ensino da dança é permeado por inúmeras expectativas e diferentes formas de linguagem. Desde os primórdios, a dança abarca saberes construídos histórica e culturalmente e suas formas de manifestação podem trazer repercussões importantes para aqueles que se apropriam dos estudos e das vivências práticas com essa forma de expressão.

Ao se expressar por meio da dança, o ser humano transmite suas expectativas, seus valores, seus conhecimentos e, principalmente, seus estados emocionais podem revelar ou despertar sentimentos importantes para aquele que dança. Entretanto, esses são aspectos nem sempre bem compreendidos, ou mesmo, desconsiderados nos processos de ensino-aprendizagem da dança.

Dessa forma, entre os vários fatores psicológicos vinculados com a performance da dança, alguns estados emocionais e de humor tornam-se relevantes. Esses se tornam

1 Endereço para correspondência: Rua Natal, 2068, Vila Belmiro, Pirassununga, SP, Brasil. CEP: 13.633-508.E-mail: priscilale128@ gmail.com capazes de desencadear aspectos que, por estarem pautados na subjetividade, podem interferir positiva ou negativamente no desenvolvimento das experiências práticas com a dança.

Um polo reconhecidamente disseminador e formador dos conhecimentos, do treinamento e da educação da dança é a Royal Academy of Dance (RAD). Essa organização propõe um planejamento dos conteúdos a serem desenvolvidos no ensino da dança. $\mathrm{O}$ intuito é o de promover, não apenas o conhecimento, mas também, maior entendimento das práticas de dança, internacionalmente, haja vista que essa escola tem suas bases em todos os continentes.

A RAD também oferece um programa de exames que se propõe a uma avaliação sistemática do progresso de estudantes de dança em diferentes idades e habilidades, garantindo a qualidade da formação para atuar como professor, bailarino ou profissional de dança. Os exames são administrados por um quadro de aproximadamente 200 examinadores de diferentes países, os quais se submetem a um rigoroso treinamento dentro da academia e, após 
aprovados, passam a ser monitorados para garantir a paridade e a confiabilidade das suas avaliações das sessões de exames.

Para se submeter aos exames da RAD, os candidatos devem desenvolver e assimilar os conteúdos inseridos no Syllabus, manual próprio, que descreve todos os exercícios, os conteúdos, as dinâmicas e os procedimentos que devem ser utilizados. Esses conteúdos estão organizados em níveis e devem ser indicados de acordo com a idade, habilidade, conhecimento e experiência dos participantes.

A postura, os níveis de coordenação motora, a técnica de execução, a utilização adequada do espaço, a fluência de movimento, a musicalidade, a expressividade, entre outros, são aspectos a serem avaliados. Essas avaliações são fundadas em experiências eminentemente práticas. Nesse sentido, pode haver alguma intercorrência envolvendo diferentes fatores, inclusive os de ordens psicológica e emocional. Nessa feita, os estados de humor podem se tornar elementos prejudiciais ou benéficos àqueles que se sujeitam a essas experiências, podendo alterar, até mesmo, o nível de performance no decorrer do desenvolvimento do exame.

Os estados de humor de bailarinos, especialmente no âmbito dos Exames da RAD fazem parte de um campo de conhecimentos ainda escasso na literatura científica. A apreensão e o entendimento de diversos aspectos subjetivos instigam questões pertinentes, que geram lacunas ainda pouco exploradas pelo meio acadêmico.

A evolução da dança é permeada por diversos estilos e técnicas que devem ser consideradas. No que se refere ao Ballet especificamente, a RAD, assim como a Cecchetti, a Vaganova e a Balanchine apresentam propostas que se tornaram exemplos de metodologias a se considerar, no espectro de técnicas de dança. Todas são reconhecidas quando se focalizam os resultados técnicos provenientes do ensino, haja vista a sistematização e o rigor com que os programas são desenvolvidos e a preparação dos profissionais atuantes.

Cada uma delas apresenta uma proposta e um caminho para o desenvolvimento da dança, mas apresentam diferenças entre si, quanto às teorias e no que concerne ao processo ensino-aprendizagem, sobretudo quanto ao grau e ordem de importância dos conteúdos a serem ensinados aos alunos. Para Cranford (2011), as técnicas anteriormente citadas têm se revelado eficazes e vêm sendo ensinadas no mundo inteiro já há vários anos. Essa autora também salienta que as técnicas focalizam caminhos específicos para treinar o corpo na arte da dança e que muitos professores afirmam receber influências de múltiplas fontes de treinamento. Para se compreender melhor a maneira como se processam as avaliações no contexto dos programas, este estudo focalizou a atenção na RAD, uma vez que essa é uma das metodologias de dança mais difundidas no mundo.

\section{A Royal Academy of Dance}

A RAD é uma organização destinada ao treinamento e educação da dança, a qual se propõe a promover o conhecimento e o entendimento dessa arte, internacionalmente. Para tanto, a proposta inclui a formação e a educação de estudantes e professores, os quais devem passar pelo sistema de exames para a obtenção de certificados, sendo que as aulas possuem conteúdos pré-estabelecidos e normas sistematizadas para essa participação com a RAD; http://www.rad.org.uk/).

Essa instituição, com sede em Londres, tem como objetivo promover o desenvolvimento contínuo da dança, dando suporte aos professores para o aperfeiçoamento de suas habilidades de ensino e transmissão de conhecimentos, bem como, para o treinamento de estudantes, buscando altos padrões de ensino-aprendizagem da dança. Para tanto, anualmente, a RAD organiza conferências, workshops, cursos de formação, aperfeiçoamento e atualização, entre outros eventos importantes na difusão da dança (http://www. rad.org.uk/).

A RAD foi fundada em 1920 e tem a rainha Elisabeth II como patronesse. Atualmente, sua metodologia é aplicada em 85 países sendo que 36 escritórios estão distribuídos por diferentes localizações, para darem suporte ao desenvolvimento das propostas. A RAD possui aproximadamente 14.000 membros associados e, no último ano, 230.000 jovens foram inscritos para os programas de exames (http://www.rad.org.uk/).

Oseu portfólio de exames éreconhecido internacionalmente e é designado para motivar os alunos de acordo com as idades e níveis de habilidades, a execução prática e o progresso dos estudantes são avaliados de forma sistemática. Os exames são dirigidos por examinadores selecionados no escritório de Londres, os quais serão deslocados para as localidades onde ocorreram as inscrições.

Entre os programas de exames oferecidos pela RAD está o Pre-School Dance Curriculum (http://www.rad.org.uk/). Este visa desenvolver habilidades para os movimentos básicos, a musicalidade, a expressividade e a criatividade e é apropriado para estudantes com faixa etária de 2 anos e meio até 5 anos. A partir dessa idade sugere-se a iniciação no programa por meio do Pre-primary in Dance, para então, prosseguir nos Graded Examinations in Dance. Esse programa busca o desenvolvimento de habilidades técnicas, musicais, e focaliza a qualidade no desempenho.

O conteúdo avaliado é composto por três disciplinas de dança: a iniciação na técnica Ballet Clássico, o Free Movement, que incorpora movimentos naturais e de estilos, como dança contemporânea e dança grega clássica, e o Character, que consiste em uma apresentação teatral de danças nacionais, com músicas especialmente adaptadas dos estilos Húngaro, Russo e Polonês. Esses conteúdos são selecionados por sua importância na história da dança.

Os Graded Examinations são organizados progressivamente em ordem de complexidade e vão do Primary ao Grade 8 Award. Para cada um desses níveis, as avaliações podem acontecer como Exames ou Aulas de Apresentação.

As Aulas de Apresentação são indicadas para aqueles que ainda não se sentem seguros, ou que encontram grandes dificuldades com os conteúdos propostos. Assim, ao invés de as sessões serem conduzidas pelo examinador, o professor faz essa opção nas inscrições e a avaliação é gerida pelo próprio professor responsável. Os alunos, nesses casos, são premiados com um certificado de participação (http://www. rad.org.uk/).

Para aqueles que estiverem inscritos para Exames, a avaliação é regida pelo próprio examinador da RAD, sendo 
estabelecida uma pontuação mínima para que o candidato tenha êxito e receba o certificado de aprovação no nível escolhido. De acordo com o índice de pontuação, a avaliação do aluno recebe uma classificação. O conteúdo desenvolvido deve estar de acordo com o nível do Syllabus escolhido e é o mesmo nos dois tipos de avaliação, Exames e Aulas de Apresentação, diferindo em alguns graus de dificuldade e procedimentos.

Outro programa de exames da RAD é o Vocational Graded Examinations in Dance, o qual visa a promover um estudo mais aprofundado do ballet clássico, por meio do desenvolvimento de habilidades musicais, técnicas e de performance. Ele introduz o trabalho de pontas para as candidatas do sexo feminino e prepara para a introdução na carreira na dança, sendo indicada para estudantes com, no mínimo, 11 anos de idade. Esse programa inicia-se no Intermediate Foundation, progredindo para o Intermediate, Advanced Foundation e para aqueles que conquistarem o Advanced Certificate e tenham habilidades técnicas, podem se submeter ao Solo Seal Award e ao mais alto Vocational Graded Examination, o qual focaliza a performance solo, sendo de grande complexidade.

Os estudantes podem começar com o Pre-school Dance Curriculum (currículo de dança pré-escolar), ir para os níveis de Pre-primary e Primary in Dance e, então, para os oito níveis de Graded Examination, ou para os níveis de Vocational Graded Examinations in Dance, de forma gradual e no momento oportuno, ou podem estudar ambas as vias simultaneamente, respeitando-se as idades mínimas sugeridas para o desenvolvimento dos conteúdos e suas habilidades.

Toda a programação dos conteúdos é apresentada em apostilas específicas para cada nível, denominadas Syllabus. Esses materiais indicam e orientam os procedimentos e as dinâmicas que deverão ser utilizadas na sala de exame e são atualizadas periodicamente. Cranford (2011) destaca que a RAD Syllabus foi introduzida em 1920 na Inglaterra, com o objetivo de aprimorar o padrão de estudo do ballet. Para essa autora, o método apresenta um programa que considera a estrutura e a integridade do corpo do bailarino, bem como, suas habilidades e limitações pessoais. O tipo de treinamento permite que se possa reduzir o risco de lesão por meio do desenvolvimento das habilidades técnicas.

Com o progresso do aluno, a ênfase é colocada no correto alinhamento da região pélvica e da coluna vertebral, no bom uso da musculatura interna da coxa e na clareza do trabalho dos pés. Além disso, não se limita ao estudo da técnica de ballet, pois os estudantes são encorajados a explorar as danças a caráter e contemporâneas, mostrando a importância de se expressar por meio dos diversos estilos de dança.

Cranford (2011) salienta que o treinamento da RAD, apesar de rigoroso, não sacrifica a individualidade do bailarino e que a RAD Syllabus reconhece e aprecia a expressão dos sentimentos dos estudantes. Assim, quando se trabalha nessas diversas áreas da técnica e da expressão, os alunos são incentivados a adequar seu treinamento ao melhor atendimento às suas capacidades individuais, às suas habilidades musicais de projeção e apresentação.

Dessa forma, por ser uma instituição de grande repercussão no universo da dança e por abarcar vivências práticas em suas avaliações, além de uma grande expectativa para essa participação, os exames propostos pela metodologia da RAD podem interferir ou trazer inúmeras repercussões nos estados de humor dos candidatos. Os estados de humor, mesmo que transitórios ou momentâneos, implicam em alterações emocionais que podem influenciar, não apenas o desempenho nas aulas e atividades práticas de dança, mas repercutir em suas percepções pessoais, seu autoconceito, nas outras etapas do método, como é o caso dos exames, foco de atenção deste estudo.

\section{Estados de Humor e Atividades Físicas}

Werneck e Navarro (2011) ressaltam que as atividades físicas trazem inúmeros benefícios, entre os quais a redução do estresse, a diminuição da ansiedade, da depressão e da hostilidade, além da melhoria do humor. Esses autores destacam que, para a regulação do humor, o exercício físico se mostra um recurso eficiente, sendo seus benefícios muito difundidos entre os profissionais da saúde, pela mídia e por pesquisadores, o que denota a importância acadêmica do assunto.

De igual modo, Panda (2011) destaca efeitos positivos da atividade física e do exercício sobre os aspectos psicológicos, emocionais e sociais, tais como: melhoria do autoconceito, da autoestima, do humor, da imagem corporal, a diminuição do estresse, da ansiedade, além de um ganho nas funções cognitivas, na autovalorização e na socialização. Para essa autora, a prática de atividades e exercícios físicos promove, inclusive, o bem-estar. $\mathrm{O}$ tema referente às relações entre atividades físicas e os estados de humor está em foco em diversas publicações, como as de Brandt, Viana, Segato e Andrade (2010), Mello, Boscolo, Esteves e Tufik (2005), Rebustini (2005), Rebustini e Machado (2012), Vieira, Fernandes, Vieira e Vissoci (2008), entre diversos outros.

Os estados de humor são variáveis psicológicas muito estudadas quando se trata do envolvimento com os exercícios, o que incentivou a validação do questionário Perfil dos Estados de Humor, o POMS (McNair, Lorr, \& Droppleman, 1971). Para Werneck (2003, 2011), os estados de humor são um indicador do bem-estar psicológico e podem ser entendidos como um estado psicológico, composto por um complexo de sentimentos positivos e negativos, os quais variam em intensidade e duração.

As emoções, os sentimentos, os afetos, e o humor são elementos essenciais que, de acordo com Panda (2011), constituem a vida afetiva do indivíduo, estando envolvidos em todas as experiências humanas. As emoções são reações afetivas geradas por um estímulo significativo. Para Rebustini (2005), a emoção incita um sentimento específico e conduz as tendências das ações.

Determinadas sensações são dominantes em certos momentos e geram mudanças no comportamento. Panda (2011) destaca que os sentimentos são estados afetivos e, quando confrontados com as emoções, são mais estáveis e menos intensos. O emocional, para essa autora, está diretamente ligado a diversos traços do humor, sejam eles negativos (tensão, raiva, fadiga e depressão) ou positivos (autoestima, vigor e bem-estar). 
O afeto é a qualidade emocional que está acompanhada de uma representação ou ideia. $\mathrm{O}$ estado de humor ou de ânimo pode ser definido como o tônus afetivo do indivíduo, o qual influencia a percepção das vivências e desempenha um papel importante nas esferas afetiva e intelectual (Gazzaniga \& Heatherton, 2005).

Os estados de humor são sentimentos subjetivos, com duração variável, podendo se refletir de forma positiva ou negativa. Segundo Brandt et al. (2010), os estados de humor incluem uma série de fatores e variáveis psicológicos, entre os quais, pode-se citar a depressão, a raiva, a confusão, a tensão, a fadiga e o vigor.

Para Morgan (1980), humor positivo é caracterizado por elevado nível de vigor (fator positivo) e baixos níveis de fadiga, tensão, depressão, confusão e raiva (fatores negativos), sendo este considerado um modelo ideal de saúde mental positiva. Entretanto, apesar da literatura ressaltar significativas relações e intercorrências entre atividade física e estados de humor, ainda existem questões não elucidadas, especialmente no que se refere às formas como esse fenômeno ocorre nas práticas de dança.

As relações existentes entre os aspectos positivos e negativos oriundos da forma como as vivências práticas com a dança e das situações em que tais práticas são avaliadas, podem interferir nas dimensões do estado de humor de seus praticantes. Assim, esta pesquisa tem como objetivo investigar o estado de humor de alunos-bailarinos, quando participam do sistema de exames da RAD.

\section{Método}

Esta pesquisa evidenciou uma natureza qualitativa, por entender, como Richardson (2008), que essa forma supera a expectativa numérica, ao evidenciar a análise e a compreensão das investigações, que se voltam para situações complexas ou estritamente particulares, como é o caso dos exames propostos pela RAD e os estados subjetivos envolvidos. Rohlfs et al. (2008) salientam a importância da pesquisa qualitativa no reconhecimento de processos psicológicos e emocionais que intervêm no desempenho do indivíduo. Para esses autores, não é possível avaliar o julgamento subjetivo apenas com métodos estatísticos, sendo necessária a avaliação do investigador em julgar se o instrumento efetivamente afere o que deveria aferir.

Contudo, é importante ressaltar, segundo esses autores, que a percepção subjetiva do sujeito participante é essencial para que se possa melhor compreender os resultados, pois a realidade investigada é percebida de maneira subjetiva, como uma síntese de múltiplas determinações, capazes de influenciar, não só os estilos e qualidade de vida, mas também, o desempenho desportivo. Nessa esfera podem ser incluídas as vivências com a dança aqui focalizadas.

O estudo aliou pesquisa bibliográfica e pesquisa exploratória. Na primeira, foi realizada uma busca em bases de dados científicos, visando a elucidar o desenvolvimento da dança, especialmente por meio da metodologia proposta pela RAD, bem como, fundamentar e compreender os estados emocionais e de humor elencados nas vivências práticas sugeridas para as avaliações que acontecem no âmbito dessa organização, objeto deste estudo.

Já a pesquisa exploratória, a qual, corroborando Gil (2007), tem por finalidade ampliar o conhecimento a respeito de determinado fenômeno explorando uma determinada realidade, visou a apreender os estados de humor dos estudantes de dança que se submetem às avaliações propostas por essa renomada organização, a RAD. Para tanto, utilizouse como instrumento para coleta de dados o Perfil de Estados de Humor (POMS; Profile of Mood States), proposto por McNair et al. (1971).

Para mensurar os estados de humor, esse instrumento é composto por 65 adjetivos, os quais focalizam a análise de seis fatores de humor: depressão, tensão, raiva, fadiga, confusão mental e vigor, sendo esse o fator de humor positivo. Rohlfs et al. (2008) ressaltam que esse teste foi desenvolvido no final da década de 1950, para a observação de estados em diferentes momentos de flutuação de humor em pacientes psiquiátricos. Os autores destacam que a tradução e a validação na versão do POMS em português foram feitas em um estudo que comprovava as alterações de humor associadas à atividade física (Peluso, 2003), o que justifica o uso desse instrumento em um estudo que abarque as atividades práticas com a dança.

O POMS é baseado em uma escala do tipo Likert (1931) de cinco pontos, sendo que, para cada adjetivo, o sujeito participante do estudo assinala opções numéricas, as quais variaram de 0 a 4, para responderem à questão de como estavam se sentindo no momento da aplicação do instrumento. Os números significaram: 0 - nada, 1 - um pouco, 2 - mais ou menos, 3 - bastante e 4 - extremamente.

A coleta dos dados aconteceu de modo bifásico e individualmente, antes e após a participação do exame da RAD, em uma escola de dança na cidade de Pirassununga/ SP - Brasil, a qual tem seu prestígio reconhecido na formação para atuação com dança. A amostra intencional foi composta por 12 sujeitos do sexo feminino, estudantes de dança, com faixa etária de 18 a 40 anos, candidatas ao exame de Grade 8 Award.

Esse exame é estruturado de forma sistemática, em que acontece uma aula com exercícios previamente preparados e estudados. As músicas utilizadas são tocadas por uma pianista credenciada pela RAD, mas escolhida pela professora responsável. Na sala de exame permanecem apenas as quatro candidatas, a pianista e a examinadora.

O Exame de Grade 8 Award encerra o programa em nível de Graded Examinations da RAD, sendo, portanto, considerado de grande complexidade. Após executarem os exercícios na barra, os quais servem apenas como aquecimento e não são avaliados, as candidatas se retiram da sala e esse exame prossegue com danças e sequências especificamente selecionadas no Syllabus da RAD de Grade 8 , pelo professor responsável, de acordo com o perfil e habilidade das candidatas.

As candidatas passam a adentrar à sala de exame de forma solo, ou seja, uma a uma, conforme a ordem indicada no formulário de inscrição. Os exercícios e danças seguem uma ordem que vai da sessão de danças baseadas no Ballet Clássico, para a sessão de Free Movement, para, então, finalizar com o Character, sendo obrigatório que cada uma 
das candidatas apresente uma das opções de danças em cada um desses três estilos de dança.

Para facilitar a comunicação entre examinador e candidatas, os exercícios são pedidos de acordo com a terminologia do Ballet Clássico, a qual é universal no estudo da dança, sendo outros termos utilizados para denominar exercícios de Free Movement, Character e outras sequências coreográficas (conteúdos avaliados igualmente à técnica de ballet clássico), que possuem nomenclaturas designadas na língua inglesa, idioma oficial para a condução dos exames da RAD.

A pesquisa respeitou todos os critérios éticos para pesquisa com seres humanos e teve a anuência de todos os participantes, após esclarecimentos sobre os procedimentos a serem realizados, propósitos da pesquisa e liberdade para desistência a qualquer momento. Após a anuência das participantes, estas assinaram o Termo de Consentimento Livre e Esclarecido. Os dados foram coletados no momento em que as candidatas chegavam à escola, antecedendo o referido exame e após a realização do mesmo.

Os dados foram analisados descritivamente, utilizandose a técnica de Análise de Conteúdo Temático proposta por Bardin (2009), por representar uma forma adequada de seleção de temas contidos nas respostas, os quais são interessantes e pertinentes ao estudo. Esse conjunto de técnicas baseia-se na análise dos temas mais recorrentes nas respostas dos sujeitos, desvelando o conteúdo e os significados contidos nas mensagens.

De acordo Rohlfs et al. (2008), a análise dos resultados obtidos por meio da aplicação do POMS inclui a divisão dos 65 itens, entre os seis fatores: tensão, depressão, raiva, vigor, fadiga e confusão. Entretanto, alguns itens faziam parte de um sétimo fator, "amabilidade", o qual foi descartado, por não ter apresentado validade e confiabilidade adequadas no processo de validação do instrumento. Dessa forma, corroborando esses autores, todos os itens permaneceram para este estudo com a dança, para que não houvesse alteração no instrumento originalmente proposto.

Devido à variação existente na indicação das intensidades propostas no POMS pelos sujeitos desta pesquisa nos pré e pós-testes, ocorreu uma dispersão dos dados. Sendo assim, as análises foram feitas e expressas, inclusive, com base nas médias, para que se pudesse obter uma referência da tendência central das respostas.

As intensidades apontadas pelos sujeitos da pesquisa para cada estado de humor indicadas nos pré e no pós-testes foram somadas individualmente, de acordo com os adjetivos correspondentes para cada fator de humor. Posteriormente, foram somadas as respostas de todas as participantes, para que se pudesse obter uma média e melhor visualizar os resultados da pesquisa.

\section{Resultados}

Os dados foram coletados antes e após a realização do exame de Grade 8 Award da RAD, sendo as intensidades das variáveis para os estados de humor das participantes do referido exame apresentadas em figuras, para melhor visualização. A Figura 1 apresenta o fator de humor positivo vigor e as variáveis dos fatores de humor negativo tensão, depressão, raiva, fadiga e confusão mental dos sujeitos da pesquisa antes e após a realização do exame de Grade 8 Award da RAD.

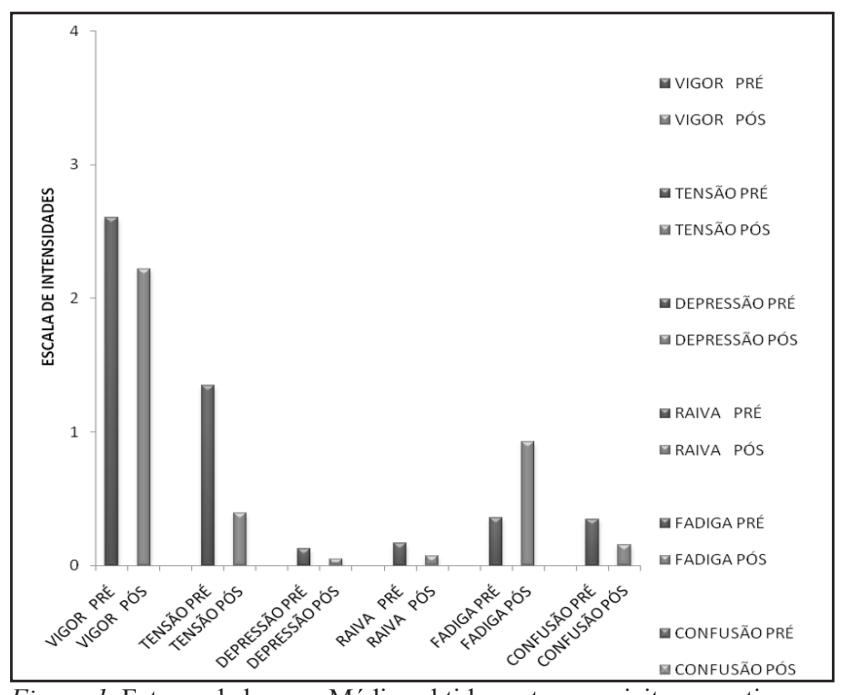

Figura 1. Fatores de humor. Médias obtidas entre os sujeitos a partir da escala de intensidades para os adjetivos referentes a vigor, tensão, depressão, raiva, fadiga e confusão, antes e após a participação do exame da RAD

Os resultados indicam uma percepção positiva dos estados de humor no pós-teste. A comparação entre os dados coletados nos pré e pós-testes evidenciou um aumento da fadiga e uma diminuição do vigor na média entre os sujeitos da pesquisa, o que pode estar relacionado ao desgaste físico decorrente das práticas, mas também, apontam para a diminuição dos estados de tensão, depressão, raiva e confusão mental.

Com a aplicação do POMS, alguns estados de humor das candidatas participantes do referido exame puderam ser diferenciados antes e depois da avaliação prática. Para este estudo, o levantamento das unidades de significados com base na técnica de Análise de Conteúdo proposta por Bardin (2009) evidenciou dois eixos referentes aos estados de humor, levados em consideração na análise. O primeiro compreendeu os fatores de humor positivo e o segundo os fatores de humor negativo.

Para a categorização dos fatores de humor positivo evidenciou-se o vigor como o fator que representa o estado de humor positivo. Brandt et al. (2010) e Rohlfs et al. (2008) destacam o vigor como a única variável positiva para a análise do POMS.

Com base na soma das intensidades apontadas nas respostas dos sujeitos, a média dos valores indica a tendência central das respostas. Assim, os resultados evidenciaram 2,60 pontos para os fatores de humor positivo no pré-teste, o que diminuiu para 2,22 pontos no pós-teste. No que se refere aos fatores de humor negativo, essa pontuação foi de 2,36 no pré-teste, passando para 1,59 no pós-teste.

A Tabela 1 apresenta a média obtida a partir da soma das intensidades apontadas para os adjetivos correspondentes, para cada fator de humor, de cada um dos sujeitos da pesquisa, nos pré e no pós-testes. 
Tabela 1. Média das intensidades apontadas para os fatores de humor

\begin{tabular}{ccccccccccccccc}
\hline & \multicolumn{2}{c}{ Vigor } & \multicolumn{2}{c}{ Tensão } & \multicolumn{2}{c}{ Depressão } & \multicolumn{2}{c}{ Raiva } & \multicolumn{2}{c}{ Fadiga } & \multicolumn{2}{c}{ Confusão } \\
\hline Sujeitos & Pré & Pós & Pré & Pós & Pré & Pós & Pré & Pós & Pré & Pós & Pré & Pós \\
\hline 1 & 2,88 & 2,88 & 0,57 & 0,57 & 0,00 & 0,00 & 0,08 & 0,08 & 0,86 & 0,86 & 0,33 & 0,33 \\
2 & 2,63 & 3,63 & 3,00 & 0,14 & 0,06 & 0,00 & 0,33 & 0,00 & 0,43 & 0,29 & 1,50 & 0,00 \\
3 & 3,00 & 1,88 & 2,14 & 0,00 & 0,31 & 0,13 & 0,42 & 0,00 & 0,71 & 2,57 & 0,83 & 0,83 \\
4 & 3,13 & 1,75 & 0,14 & 0,57 & 0,00 & 0,00 & 0,00 & 0,00 & 0,00 & 0,86 & 0,00 & 0,00 \\
5 & 2,25 & 1,88 & 1,14 & 0,00 & 0,00 & 0,00 & 0,00 & 0,00 & 0,14 & 0,86 & 0,00 & 0,00 \\
6 & 2,75 & 2,13 & 0,71 & 0,00 & 0,00 & 0,00 & 0,00 & 0,00 & 0,00 & 0,29 & 0,17 & 0,00 \\
7 & 3,00 & 2,13 & 1,29 & 0,14 & 0,00 & 0,00 & 0,00 & 0,00 & 0,43 & 1,14 & 0,33 & 0,33 \\
8 & 1,63 & 1,63 & 1,71 & 1,71 & 0,13 & 0,13 & 0,25 & 0,25 & 0,00 & 0,86 & 0,00 & 0,00 \\
9 & 0,88 & 1,13 & 1,29 & 0,00 & 1,00 & 0,31 & 0,83 & 0,50 & 1,00 & 0,71 & 0,50 & 0,17 \\
10 & 3,50 & 2,38 & 0,86 & 0,29 & 0,00 & 0,00 & 0,00 & 0,00 & 0,00 & 1,00 & 0,17 & 0,00 \\
11 & 3,13 & 2,13 & 0,71 & 0,43 & 0,00 & 0,00 & 0,08 & 0,00 & 0,71 & 1,00 & 0,00 & 0,00 \\
12 & 2,50 & 3,13 & 2,57 & 0,86 & 0,00 & 0,00 & 0,00 & 0,00 & 0,00 & 0,71 & 0,33 & 0,17 \\
\hline Média & 2,60 & 2,22 & 1,35 & 0,39 & 0,13 & 0,05 & 0,17 & 0,07 & 0,36 & 0,93 & 0,35 & 0,15 \\
\hline
\end{tabular}

Notas. S: sujeito. Vigor: fator de humor positivo. Tensão, depressão, raiva, fadiga e confusão: fatores de humor negativo. Média: valores baseados na soma das intensidades apontadas para a escala POMs

Tabela 2. Percentuais das intensidades apontadas na escala

\begin{tabular}{cccccccccccccc}
\hline & \multicolumn{2}{c}{ Vigor } & \multicolumn{2}{c}{ Tensão } & \multicolumn{2}{c}{ Depressão } & \multicolumn{2}{c}{ Raiva } & \multicolumn{2}{c}{ Fadiga } & \multicolumn{2}{c}{ Confusão } \\
\hline Escala & Pré & Pós & Pré & Pós & Pré & Pós & Pré & Pós & Pré & Pós & Pré & Pós \\
& $\%$ & $\%$ & $\%$ & $\%$ & $\%$ & $\%$ & $\%$ & $\%$ & $\%$ & $\%$ & $\%$ & $\%$ & $\%$ \\
$4-3$ & 62,5 & 45 & 19 & 4,8 & 1 & 0,5 & 1,4 & 0,7 & 2,4 & 13,1 & 1,4 & 1,4 \\
$2-0$ & 37,5 & 55 & 81 & 95,2 & 99 & 99,5 & 98,6 & 99,3 & 97,6 & 86,9 & 98,6 & 98,6 \\
\hline
\end{tabular}

Notas. Escala de 4-3 referente ao percentual obtido para as intensidades "extremamente e bastante". Escala 2-0 referente ao percentual das intensidades

"mais ou menos, um pouco e nada" apontadas para a escala POMs

Complementando esses resultados, a Tabela 2 apresenta dados percentuais relativos às intensidades percebidas pelos sujeitos, de acordo com a escala proposta para os fatores de Humor:

\section{Discussão}

O vigor é um dos fatores de humor avaliados pelo POMS e, de acordo com Terry (1995), sugere sinônimos que indiquem animação, energia, atividade. Assim, para esse estudo, a análise do vigor foi feita a partir das intensidades indicadas pelos sujeitos da pesquisa para os adjetivos: animado, ativo, enérgico, alegre, alerta, eficiente, cheio de energia e vigoroso. Os resultados evidenciaram que o vigor aumentou para três e diminuiu para sete participantes, sendo que, para dois, esse fator permaneceu inalterado.

$\mathrm{O}$ fato de sete participantes evidenciarem intensidades mais elevadas para o vigor no pré-teste pode significar, conforme Benedetti, Oliveira e Lipp (2011), que os sintomas mais pontuados pressupõem uma reação natural por parte dos participantes em período de pré-competição. Para essas autoras, ocorre um aumento de motivação e entusiasmo para o enfrentamento da situação, o que, possivelmente, está relacionado à expectativa de desempenho frente à competição.

Já a diminuição do fator vigor no pós-teste indica perda de disposição e energia física, devido, provavelmente, ao cansaço físico, conforme Rohlfs et al. (2008). Entretanto, essas divergências percebidas corroboram Brandt et al. (2010), para os quais é preciso levar em conta as particularidades de cada atleta e para este estudo de cada estudante de dança.

Um dado interessante foi apresentado nos estudos de Vieira et al. (2008) no que se refere à questão de gênero, os quais realizados com atletas de voleibol verificou-se maior instabilidade no humor na equipe feminina. Ainda de acordo com esses autores, essas atletas apresentaram vigor mais baixo, maior propensão à fadiga e ao estresse, fato que pode ser observado também neste estudo com a dança e pode ter apresentado ressonâncias por todas as participantes serem do sexo feminino.

No que tange à categorização dos fatores de humor negativo foram consideradas as variáveis para tensão, depressão, raiva, fadiga e confusão mental. A tensão é definida por Terry (1995) como um estado de tensão musculoesquelética, agitação e inquietação. Para esse estudo, ela foi analisada com base nas intensidades apresentadas para: tenso, a ponto de explodir, apavorado, preocupado, irrequieto, nervoso e ansioso.

Assim, para as estudantes de dança participantes deste estudo, o fator tensão aumentou para uma, diminuiu para nove e não sofreu alterações entre duas, sendo que quatro participantes indicaram a intensidade 0 , ou seja, nada para todas os itens dessa variável no pós-teste. A tensão foi 
percebida em intensidades mais elevadas no pré-teste. Essa predominância para um estado de tensão nos momentos que antecederam o exame prático da RAD na amostra estudada pode estar relacionada com as inferências feitas por Benedetti et al. (2011), para as quais a tensão é observada no atleta quando em situação de pré-competição e estão associadas a fatores de estresse, à expectativa de desempenho e ao medo de não estar preparado.

A tensão, segundo Rebustini e Machado (2012), aponta para uma tendência clara de redução no seu valor após a atividade. Vieira et al. (2008) argumentam que, durante uma competição, os estados de humor se alteram conforme a atuação da equipe, o que pode ter ocorrido por meio de uma percepção positiva em relação à participação e performance no exame, reduzindo os níveis de tensão no pós-teste.

Outra consideração que precisa ser tomada por base são as características e as particularidades de cada indivíduo, conforme salientado por Brandt et al. (2010). Rebustini e Machado (2012) ressaltam a probabilidade de as alterações de humor estarem relacionadas ao esporte, podendo-se aqui incluir a dança, foco deste estudo.

Entretanto, para esses autores é fundamental que as mudanças de humor sejam comparadas com os níveis dos próprios participantes em diversos momentos, para que se possam compreender as flutuações intraindividuais dos estados de humor e as formas como estes interferem no desempenho atlético. Esses autores anteriormente citados salientam que, cada modalidade esportiva tem suas próprias dinâmicas e culturas, o que desencadeia interpretações, reações e consequências distintas.

Outro fator de humor negativo é a depressão, a qual, para Beck e Clark (1988) está associada à indicação de humor deprimido, baixa autoestima, estado de inadequação pessoal, autovalorização negativa, dificuldade de ajustamento, tristeza, isolamento, culpa, entre outros. Assim, essa variável foi avaliada pelas intensidades indicadas para: infeliz, arrependido, apático, triste, melancólico, sem esperança, indigno, sentindo-se só, sentindo-se miserável, amargurado, deprimido, desamparado, enganado, inútil, esquecido e culpado.

O fator depressão não apresentou indicadores de aumento no presente estudo, mas obteve uma diminuição entre três participantes, sendo que uma dessas estudantes assinalou a opção nada no pós-teste, para todos os itens que compuseram essa variável. Entre nove participantes, esse fator de humor não alterou, sendo que oito delas assinalaram nada para todas os adjetivos, tanto no pré quanto no pós-teste.

A prática de exercícios físicos, de acordo com Antes et al. (2012), contribui para o reequilíbrio emocional, mostrando-se importante na diminuição de sintomas depressivos. Carter, Callaghan, Khalil e Morres (2012) acrescentam que altos índices de depressão têm sido associados à falta de atividades físicas e, ainda, que a participação nos esportes reduz o risco de se desenvolver a depressão.

Para Carter et al. (2012), o exercício traz efeitos favoráveis para a autoestima, autovalorização e um impacto positivo sobre o humor. A depressão foi um fator que, entre as participantes deste estudo, apresentou-se em baixa intensidade, tendo sido apontada apenas por três participantes, o que indica que esta se tornou uma variável pouco significativa para este estudo.

Para o fator raiva, de igual modo negativo, foram considerados sentimentos relacionados à antipatia e hostilidade, conforme indicado em Spielberger (1991). Dessa forma, foram analisadas intensidades apontadas para: zangado, irritado, resmungão, rancoroso, aborrecido, ressentido, pronto para brigar, desesperado, rebelde, furioso, mal humorado e aterrorizado.

De igual modo à depressão, o fator raiva não aumentou, sendo que diminui para quatro e manteve-se inalterado para oito participantes, além disto, três participantes apontaram nada para todos os itens dessa variável de humor no pós-teste e seis para todas as variáveis, tanto no pré como no pós-teste. Alterações nessa variável também podem ser atribuídas a fatores externos à competição (Brandt et al., 2010), ou ao resultado das suas atuações no decorrer do exame (Rohlfs et al., 2008).

Essas alterações podem representar motivos para que quatro participantes tenham indicado esse estado de humor no pré-teste, entretanto, o fator raiva diminuiu após o exame. Assim, para essas quatro participantes, ocorreu uma percepção positiva em relação à sua atuação e performance no decorrer do exame, alterando esse estado de humor.

Já para confusão mental, foram considerados os estados de atordoamento e outros, relacionados à incerteza e à instabilidade, o que, de acordo com Beck e Clark (1988) situa-se, possivelmente, como resposta à ansiedade e à depressão. Assim, neste estudo, essa variável analisou as intensidades indicadas para: confuso, trêmulo, incapaz de se concentrar, atrapalhado, atordoado, incerto sobre as coisas desorientado, esquecido.

No que se refere à confusão mental, assim como ocorreu com a depressão e a raiva, não foi percebido aumento para esse fator. Os dados indicaram sua diminuição entre cinco participantes e a não alteração desse estado para sete. Para as estudantes que diminuíram essa variável de humor, três assinalaram a intensidade nada em todos os itens correspondentes no pós teste e quatro fizeram o mesmo, tanto no pré, quanto no pós-teste.

Já o fator fadiga, para Lane e Terry (2000) é representado por um estado de apatia, esgotamento e um baixo nível de energia. Nessa feita, foram avaliadas as intensidades para: esgotado, fatigado, desanimado, exausto, lerdo, cansado e sem forças.

A fadiga foi um fator que aumentou entre nove estudantes participantes deste estudo, diminuiu para duas e não alterou para uma, sendo que cinco indicaram a intensidade nada ou 0 apenas no pré-teste. Assim, os elevados níveis de fadiga são, para Rohlfs et al., (2008), de certa forma, esperados após a prática esportiva, sendo resultado do desgaste físico. Esse fator apresentou-se neste estudo relacionado ao fator positivo vigor, conforme evidenciado na Figura 2.

Após os exames da RAD, o fator vigor sofreu alteração, ou seja, diminuiu com a participação no exame, e a fadiga teve sua intensidade aumentada. Corroborando Rohlfs et al. (2008), infere-se a ocorrência do cansaço físico como reação ao fator fadiga, sendo esta uma atribuição de ordem fisiológica. 


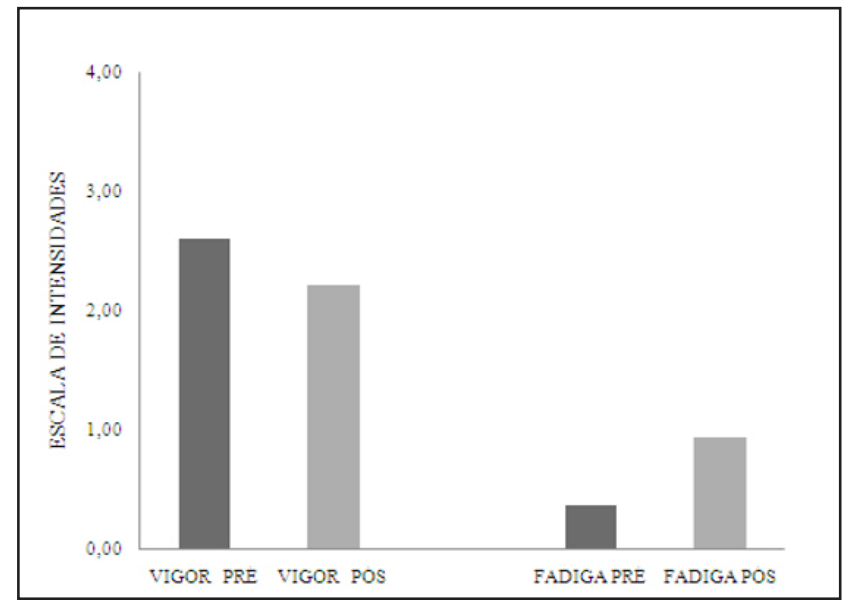

Figura 2. Relações entre fadiga e vigor. Comparação entre as médias obtidas para vigor e fadiga no pré e no pós-teste

Esses resultados com a dança diferem daqueles de Panda et al. (2011), no que se refere à relação entre o aumento do vigor e a redução das outras cinco variáveis. Para esses autores, o exercício físico aumenta a energia e a força física, ou seja, o fator positivo do estado de humor, no caso, o vigor físico, e, por isso, reduz os fatores negativos do estado de humor referentes à tensão, depressão, raiva, fadiga e confusão mental, melhorando consideravelmente o estado de humor.

Entre as estudantes de dança, mesmo com a diminuição do vigor e a percepção de aumento da fadiga, os resultados evidenciaram uma percepção positiva dos estados de humor no pós-teste, por meio da redução dos estados de depressão, tensão, raiva e confusão. Ainda, no que se refere aos itens descartados por não apresentarem confiabilidade na validação do instrumento, os quais não foram incluídos para a análise dos fatores anteriormente citados, mas foram respondidos pelos sujeitos desta pesquisa, esses mostraram-se presentes com altas intensidades no pós-teste.

Desta forma, as intensidades apontadas para os adjetivos amistoso, lúcido, atencioso, bondoso, solidário, confiante, despreocupado, prestativo e relaxado aumentaram no pósteste. Esses dados reforçaram as evidências de uma percepção positiva em relação à participação no exame, substanciando os fatores de humor positivo.

\section{Considerações Finais}

A intenção deste estudo foi investigar o estado de humor de alunos-bailarinos, quando participavam do sistema de Exames da RAD. Nessa feita, pode-se concluir que, após a realização do exame de Grade 8 Award da RAD houve a predominância de indicadores de uma tendência à melhoria geral no estado de humor. $\mathrm{O}$ estudo concluiu que o exercício físico, por meio da prática de dança, tem associação positiva no estado de humor.

Ainda, inserida no contexto de uma avaliação provavelmente geradora de grandes expectativas, tensão e fadiga, as práticas de dança atuam favoravelmente na percepção de estados afetivos positivos. Assim, atuam na redução de fatores como depressão, raiva e confusão mental, o que comprova seu potencial para interagir positivamente no humor das estudantes de dança.

Desta forma, pode-se inferir, conforme Rebustini e Machado (2012) e Brandt et al. (2010), que os fatores relacionados às especificidades da atividade, no caso por meio das práticas de dança, podem alterar os estados de humor, nesse caso positivamente. Entretanto, novos estudos se fazem necessários, no intuito de aprimorar os sistemas de avaliação, assim como, as metodologias de ensino da dança, subsidiando novas abordagens acerca dos estados subjetivos envolvendo a prática e a formação técnica em dança, aspectos ainda pouco explorados em âmbito acadêmico.

\section{Referências}

Antes, D. L., Rossato, L. C., Souza, A. G., Benedetti, T. R. B., Borges, G. F., \& Mazo, G. Z.. (2012). Índice de aptidão funcional geral e sintomas depressivos em idosos. Revista Brasileira de Cineantropometria \& Desempenho Humano, 14(2), 125-133.

Bardin, L. (2009). Análise de conteúdo (5. ed.) Lisboa: Edições 70.

Beck A. T., \& Clark, D. A. (1988). Anxiety and depression: An information processing perspective. Anxiety Research, 1, 23-56.

Benedetti, E., Oliveira, R. L., \& Lipp, M. E. N. (2011). Nível de stress em corredores de maratona amadores em período de pré-competição. Revista Brasileira de Cineantropometria \& Desempenho Humano, 19(3), 5-13.

Brandt, R., Viana, M. S., Segato, L., \& Andrade, A. (2010). Estados de humor de velejadores durante o Pré-Panamericano. Motriz, 16(4), 834-40.

Carter, T., Callaghan, P., Khalil, E., \& Morres, I. (2012). The effectiveness of a preferred intensity exercise program on the mental health outcomes of young people with depression: A sequential mixed methods evaluation. BMC Public Health, 12, 187. doi:10.1186/1471-2458-12-187

Cranford, M. K. (2011). Research in the development of curricula in dance through the study of historical techniques (Unpublished doctoral dissertation). Meredith College, Raleigh, NC, USA.

Gazzaniga, M. S., \& Heatherton, T. F. (2005). Ciência psicológica: Mente, cérebro e comportamento. Porto Alegre, RS: Artmed.

Gil, A. C. (2007). Como elaborar projetos de pesquisa (4. ed.). São Paulo, SP: Atlas.

Lane, A. M, \& Terry, P. C. (2000). The nature of mood: Development of a conceptual model with a focus on depression. Journal of Applied Sport Psychology, 12, 16-33.

Likert, R. (1931). A technique for the measurement of attitudes. Archives of Psychology. New York, NY: Columbia University Press.

Mcnair, D. M., Lorr, M., \& Droppleman L. F. (1971). Manual for the profile of mood states. San Diego, CA: Educational and Industrial Testing Services.

Mello, M. T., Boscolo, R. A., Esteves, A. M., \& Tufik, S. (2005). $\mathrm{O}$ exercício físico e os aspectos psicobiológicos. Revista Brasileira de Medicina do Esporte, 11(3), 197-207.

Morgan, W. P. (1980). Test of champions: The iceberg profile. Psychology Today, 14(11), 92-108 
Panda, M. D. J. (2011). A influência de um programa de exercícios físicos no estado emocional dos indivíduos cadastrados no ESF/Primavera. Biomotriz, 5, novembro.

Peluso M. A. M. (2003). Alterações de humor associadas a atividade fisica intensa (Unpublished doctoral dissertation). Universidade de São Paulo, São Paulo.

Rebustini, F. (2005). A Interferência dos fatores externos sobre os estados de humor em jovens atletas de voleibol (Unpublished doctoral dissertation). Universidade Estadual Paulista, Rio Claro.

Rebustini, F., \& Machado, A. A. (2012). Dinâmicas sociais e estados de humor. Motriz: Revista de Educação Física, 18(2), 233-244.

Richardson, R. J. (2008). Pesquisa social: Métodos e técnicas. São Paulo, SP: Atlas.

Rohlfs, I. C. P. D. M., Rotta, T. M., Luft, C. D. B., Andrade, A., Krebs, R. J., \& Carvalho, T. D. (2008). A escala de humor de Brunel (Brums): Instrumento para detecção precoce da síndrome do excesso de treinamento. Revista Brasileira de Medicina do Esporte, 14(3), 176-181.
Spielberger, C. D. (1991). Manual for the state-trait angerexpression inventory. Odessa, FL: Psychological Assessment Resources.

Terry, P. C. (1995). The efficacy of mood state profiling among elite performers: A review and synthesis. The Sport Psychologist, 9, 309-324.

Vieira, L. F., Fernandes, S. L., Vieira, J. L. L., \& Vissoci, J. R. N. (2008). Estado de humor e desempenho motor: Um estudo com atletas de voleibol de alto rendimento. Revista Brasileira de Cineantropometria \& Desempenho Humano, 10(1), 62-68.

Werneck, F. Z. (2003). Efeitos psicofisiológicos agudos do exercício aeróbio e contra-resistência em diferentes intensidades (Dissertação de Mestrado). Universidade Gama Filho, Rio de Janeiro, RJ, Brasil.

Werneck, F. Z., \& Navarro, C. A. (2011). Nível de atividade física e estado de humor em adolescentes. Psicologia: Teoria e Pesquisa, 27(2), 189-193. 